\title{
Article \\ Quantum Calculations of VX Ammonolysis and Hydrolysis Pathways via Hydrated Lithium Nitride
}

\author{
Calen J. Leverant $\left.{ }^{1,2}{ }^{(}\right)$, Chad W. Priest ${ }^{1}$, Jeffery A. Greathouse ${ }^{1}$, Mark K. Kinnan ${ }^{1}$ and Susan B. Rempe ${ }^{1, *}$ \\ 1 Sandia National Laboratories, Albuquerque, NM 87185, USA; clevera@sandia.gov (C.J.L.); \\ chadpriest01@gmail.com (C.W.P.); jagreat@sandia.gov (J.A.G.); mkkinna@sandia.gov (M.K.K.) \\ 2 Department of Chemical Engineering, University of Florida, Gainesville, FL 32611, USA \\ * Correspondence: slrempe@sandia.gov
}

check for updates

Citation: Leverant, C.J.; Priest, C.W.; Greathouse, J.A.; Kinnan, M.K.; Rempe, S.B. Quantum Calculations of VX Ammonolysis and Hydrolysis Pathways via Hydrated Lithium Nitride. Int. J. Mol. Sci. 2021, 22, 8653. https://doi.org/10.3390/ ijms22168653

Academic Editor: Luísa Margarida Martins

Received: 15 June 2021

Accepted: 2 August 2021

Published: 11 August 2021

Publisher's Note: MDPI stays neutral with regard to jurisdictional claims in published maps and institutional affiliations.

Copyright: (c) 2021 by the authors. Licensee MDPI, Basel, Switzerland. This article is an open access article distributed under the terms and conditions of the Creative Commons Attribution (CC BY) license (https:// creativecommons.org/licenses/by/ $4.0 /)$.

\begin{abstract}
Recently, lithium nitride $\left(\mathrm{Li}_{3} \mathrm{~N}\right)$ has been proposed as a chemical warfare agent (CWA) neutralization reagent for its ability to produce nucleophilic ammonia molecules and hydroxide ions in aqueous solution. Quantum chemical calculations can provide insight into the $\mathrm{Li}_{3} \mathrm{~N}$ neutralization process that has been studied experimentally. Here, we calculate reaction-free energies associated with the $\mathrm{Li}_{3} \mathrm{~N}$-based neutralization of the CWA VX using quantum chemical density functional theory and $\mathrm{ab}$ initio methods. We find that alkaline hydrolysis is more favorable to either ammonolysis or neutral hydrolysis for initial P-S and P-O bond cleavages. Reaction-free energies of subsequent reactions are calculated to determine the full reaction pathway. Notably, products predicted from favorable reactions have been identified in previous experiments.
\end{abstract}

Keywords: VX; aminolysis; base hydrolysis; decontamination; Hartree-Fock; density functional theory; chemical warfare agent

\section{Introduction}

Organophosphates (OPs), a class of nerve agents and pesticides, are among the most toxic of chemical warfare agents (CWAs) [1]. Upon exposure, OPs attack the central nervous system, causing involuntary bodily functions such as seizures. OPs have binding affinities similar to that of the neurotransmitter acetylcholine, allowing OPs to inhibit the action of acetylcholinesterase in neuromuscular junctions, disrupting the breakdown of the neurotransmitter [2-4]. The neutralization of OP compounds can be achieved through oxidation [5,6], enzyme degradation [7-9], hydrolysis [10-12], and incineration [13]. Nevertheless, each method is not without its limitations. Oxidation requires large excesses of oxidizing agents and is not very selective [6,14]. Enzymes used in CWA degradation are not stable and cannot be stored for long periods of time [15]. Hydrolysis often uses a large quantity of water [14]. Finally, incineration requires that the CWAs are moved to facilities with the appropriate equipment [16], and thus cannot be used in many locations.

Of the OP CWAs, ethyl(\{2-[bis(propan-2-yl)amino]ethyl\}sulfanyl)(methyl)phosphinate, or VX, is among the most toxic. Like most OPs, it contains a pentavalent central phosphorous atom, $\mathrm{P}(\mathrm{V})$. It has a four-coordinate chiral center at the $\mathrm{P}(\mathrm{V})$-atom, with two enantiomer forms (S)-VX and (R)-VX. The structure contains a phosphoester (P-OR), a methyl $\left(\mathrm{P}-\mathrm{CH}_{3}\right)$, a terminal oxide $(\mathrm{P}=\mathrm{O})$, and a phosphothiol $\left(\mathrm{P}^{-\mathrm{SR}^{\prime}}\right)$ bond. Here, $\mathrm{R}$ is an ethyl group and $\mathrm{R}^{\prime}$ is a complex constituent containing a (diisopropylamino)ethyl chain.

Molecular modeling is a useful tool to study CWA properties such as liquid structure [17,18], adsorption [19-21], and reactivity [22]. Quantum methods, specifically density functional theory (DFT) and ab initio techniques, are ideally suited to investigate fundamental reaction pathways of these compounds. Understanding the mechanistic steps involved in the decomposition of toxic chemicals such as CWAs continues to be an active area of research [23]. Many computational efforts have studied decontamination of VX, 
or its analogues (e.g., O,S-dimethyl methylphosphonothiolate) by different chemical processes. These include neutral hydrolysis, alkaline hydrolysis, oxidation, and aminolysis reactions $[10,12,22,24,25]$. Most of these chemical decontamination processes rely on a nucleophile. For these compounds, nucleophilic reactions can undergo two competing solvolysis reaction pathways: P-S or P-O bond cleavage [6,26,27], shown in Scheme 1 for alkaline hydrolysis. P-O cleavage produces toxic EA-2192 (S-[2-(diisopropylamino)ethyl] hydrogen methylphosphonothioate), while P-S cleavage yields the non-toxic EMPA (ethyl methylphosphonic acid). Alkaline hydrolysis of VX yields 13\% EA-2192 and 87\% EMPA [6]. In earlier computational work, Patterson and coworkers used a combination of DFT and Hartree-Fock (HF) methods to study the alkaline hydrolysis of sarin and OP compounds [10-12]. For VX, their results showed that the reaction pathway involving P-S bond cleavage is thermodynamically favorable compared with P-O cleavage [12]. The decomposition of VX catalyzed by the hydroxide or hydroperoxide anions also showed that the P-S cleavage is the most favorable thermodynamic pathway [11]. As validation of their methods, the calculated enthalpy of activation for sarin agrees well with the experiment [12]. Mandal et al. used DFT methods to examine the P-O and P-S bond cleavage reaction pathways in the VX analogue, O,S-dimethyl methylphosphonothiolate, in the gas phase and in the presence of various implicit solvents [24]. Although previous calculations suggested that P-S bond cleavage is approximately $5-10 \mathrm{kcal} / \mathrm{mol}$ more favorable than $\mathrm{P}-\mathrm{O}$ bond cleavage in similar compounds [11,12], results from Mandal et al. indicate that breaking either bond is equally favorable [24]. They also showed that within the COSMO implicit solvent model, the type of solvent had little effect on the barrier heights or net reaction energies [24].

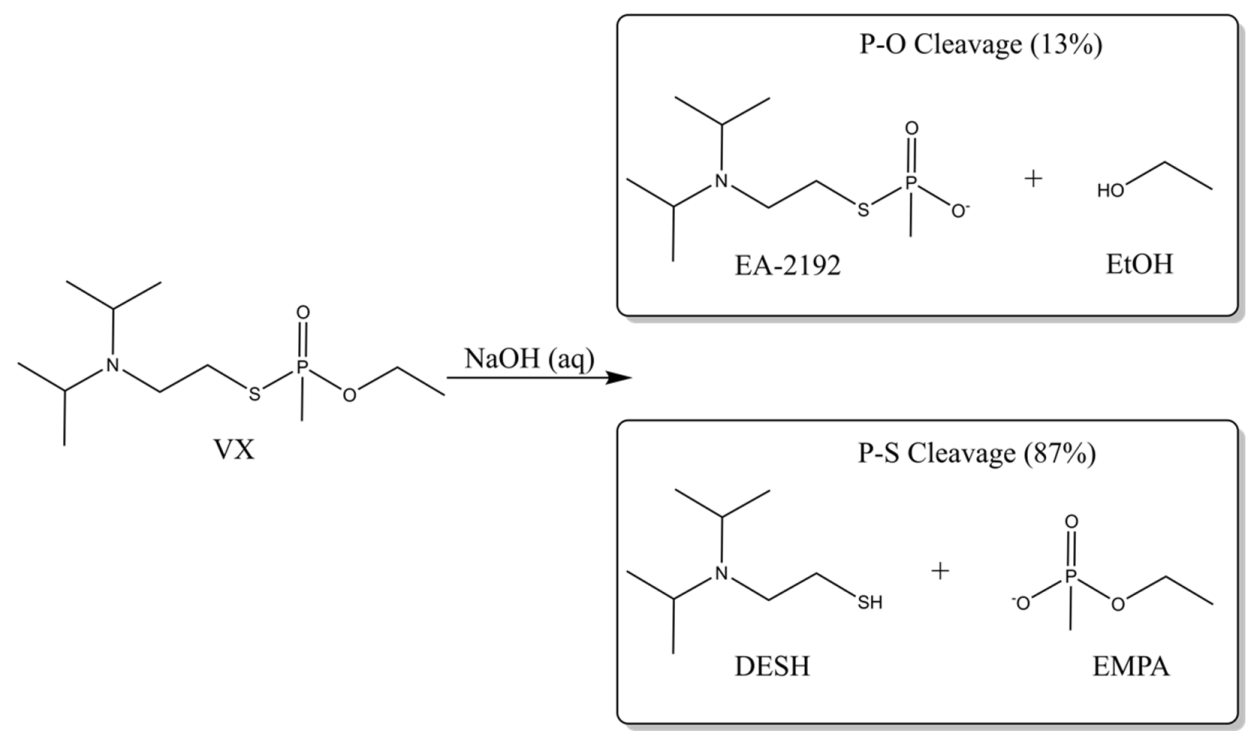

Scheme 1. Alkaline hydrolysis of VX resulting in EA-2192 from P-O cleavage or EMPA from P-S cleavage.

Recently, $\mathrm{Li}_{3} \mathrm{~N}$ has been proposed as a multifunctional reagent for broadband CWA neutralization, with the objective to use a minimal amount of the reagent to disable bulk CWAs through neutralization or solidification $[28,29]$. When $\mathrm{Li}_{3} \mathrm{~N}$ is hydrated, hydroxide ions and ammonia are generated, both of which can serve as nucleophiles in the decontamination of CWAs (Schemes 1 and 2). Here, hypothesized $\mathrm{NH}_{3}$ ammonolysis products include DIEMPAT (S-(2-(diisopropylamino) ethyl) P-methyl phosphonamidothioate) from P-O cleavage, and EMPAM (ethyl P-methyl phosphonamidite) from P-S cleavage. This work aims to explore the complete decontamination of VX from base hydrolysis and ammonolysis processes in the $\mathrm{Li}_{3} \mathrm{~N}$ aqueous environment. These reactions can contribute toward the development of new decontamination methods and to further understand the $\mathrm{Li}_{3} \mathrm{~N}$ CWA decontamination process. 


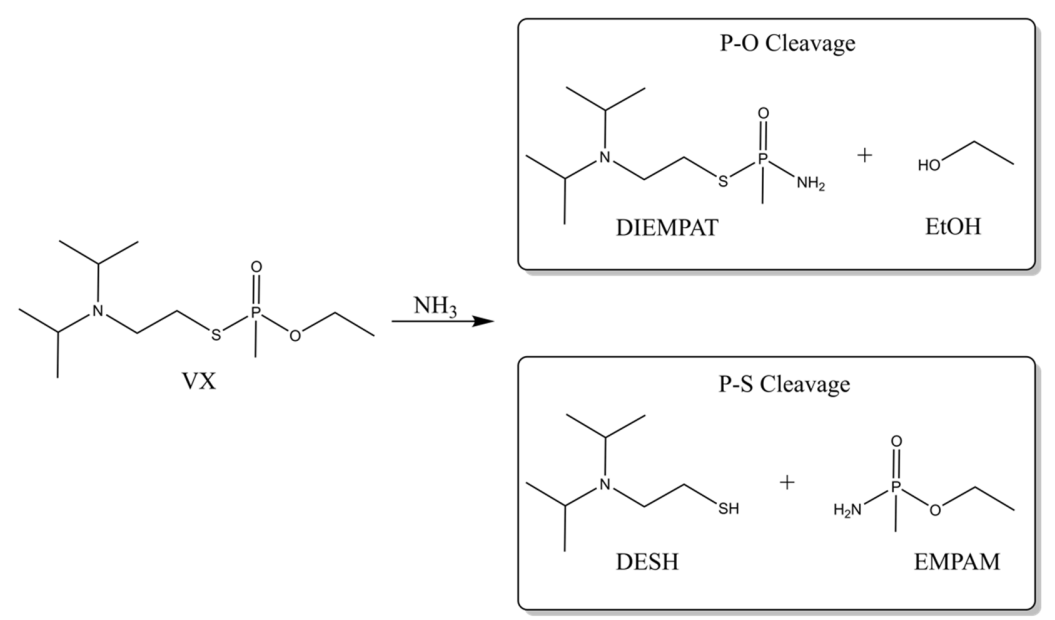

Scheme 2. Ammonolysis of $\mathrm{VX}$ with $\mathrm{NH}_{3}$, resulting in DIEMPAT from P-O cleavage or EMPAM from P-S cleavage.

\section{Results and Discussions}

The chemical structures and the geometry-optimized structures for the VX reaction products from P-O and P-S bond cleavage are shown in Figure 1 and Figure S1 (see Supplementary Materials), respectively. All reaction pathway figures list the solvation model-based density (SMD) HF $\otimes G$ values at $300 \mathrm{~K}$ with water as a solvent (HF-S). The gas phase $\mathrm{HF} \otimes G$ values (HF) as well as the gas phase and implicit (water) solvent B3LYP values (B3LYP and B3LYP-S) can be found in the corresponding tables.<smiles></smiles>

vx<smiles>CC(C)N(CCS)C(C)C</smiles>

DESH<smiles>CC(C)N(CCN)C(C)C</smiles>

$\mathrm{DENH}_{2}$<smiles>CC(C)N(CCSSCCN(C(C)C)C(C)C)C(C)C</smiles>

$(\mathrm{DES})_{2}$<smiles>CC(C)N(CCSP(C)(=O)O)C(C)C</smiles>

EA-2192<smiles>CCOP(C)(N)=O</smiles>

EMPAM<smiles>CC(C)N(CCSP(C)(N)=O)C(C)C</smiles>

DIEMPAT<smiles>CCOP(C)(=O)O</smiles>

EMPA<smiles>CP(N)(N)=O</smiles>

MPD<smiles>CP(N)(=O)O</smiles>

MPPAA<smiles>CP(=O)(O)O</smiles>

MPA<smiles>CCO</smiles>

EtOH

Figure 1. Chemical structure of VX, VX hydrolysis products, and VX ammonolysis products. VX = Ethyl (\{2-[bis(propan-2-yl)amino]ethyl $\}$ sulfanyl)(methyl)phosphinate, $(\text { DES })_{2}=$ VX Disulfide, DESH = Diisopropylamino ethanethiol, EA-2192 = S-(2-(diisopropylamino)ethyl) O-hydrogen methylphosphonothioate, DIEMPAT = S-(2-(diisopropylamino)ethyl) P-methyl phosphonamidothioate, $\mathrm{DENH}_{2}=\mathrm{N}, \mathrm{N}$-Diisopropylethylenediamine, EMPAM = Ethyl P-methyl phosphonamidite, $\mathrm{EMPA}=$ Ethyl methylphosphonic acid, MPD = P-Methylphosphonic diamide, MPPAA = P-methylphosphonamidic acid, MPA = Methylphosphonic acid, EtOH = Ethanol. 


\subsection{Neutral Hydrolysis}

Small-scale experiments have shown that VX can be completely hydrolyzed into less toxic products in 30-60 days at room temperature [30]. While alkaline hydrolysis cleaves both the P-S and P-O bonds, creating a mix of toxic and non-toxic products, hydrolysis at neutral $\mathrm{pH}$ cleaves only the P-S bond, resulting in non-toxic products $[30,31]$. The neutral hydrolysis reaction energies for the VX P-S and P-O bond cleavages are shown in Figure 2. In agreement with the earlier experimental studies [30,31], we observe a much more favorable $\otimes G$ value for the P-S bond cleavage as opposed to the P-O bond cleavage $(-15.06 \mathrm{kcal} / \mathrm{mol}$ vs. $-1.11 \mathrm{kcal} / \mathrm{mol})$. No experimental observations have shown cleavage of P-C bonds. As shown in Table 1, similar $\otimes G$ values are obtained from HF and B3LYP methods for P-O bond cleavage $\left(\otimes G_{2}\right)$. The methods differ in P-S cleavage energy $\left(\otimes G_{1}\right)$, with HF predicting more favorable reactions in gas and solvated phases.

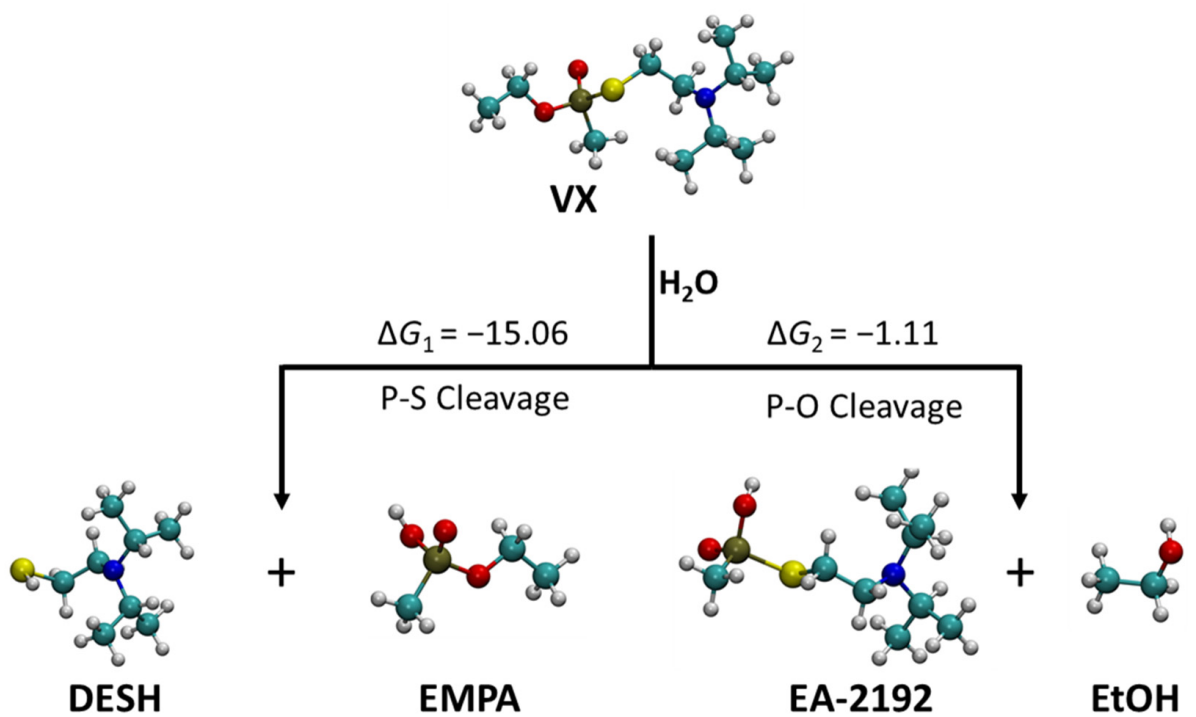

Figure 2. VX neutral hydrolysis pathway via P-S and P-O bond cleavages.

Table 1. Reaction-free energies $(\mathrm{kcal} / \mathrm{mol})$ for various computational methods for the reaction pathways 1 and 2 in Figure 2.

\begin{tabular}{ccccc}
\hline & HF-S $^{\text {a }}$ & HF & B3LYP-S $^{\text {a }}$ & B3LYP \\
\hline$\otimes G_{1}$ & -15.06 & -19.91 & -12.27 & -12.54 \\
$\otimes G_{2}$ & -1.11 & -0.32 & -1.08 & 0.33 \\
\hline
\end{tabular}

${ }^{a}$ Calculations with implicit solvent background.

\subsection{Alkaline Hydrolysis}

Hydrolysis of VX in highly basic conditions is known to produce $87 \%$ non-toxic EMPA and 13\% toxic EA-2192 (Scheme 1) [6,10]. Reaction-free energies for the initial P-O and $\mathrm{P}$-S cleavage steps (Figure 3 ) are significantly more favorable at high $\mathrm{pH}$ than in neutral solution. We show the full reaction pathway for VX with $\mathrm{OH}^{-}$in Figure 3. Both P-S and PO bond cleavages are favorable, with the P-S pathway being $~ 11 \mathrm{kcal} / \mathrm{mol}$ more favorable. Our computed $\otimes G$ values are similar to previously reported values by Daniel et al. [10].

While previous studies have looked at energy barriers and transition states of the initial P-S and P-O bond cleavages [10,12,24], it is important to examine the full reaction pathway to determine the fate of EA-2192. After the initial cleavage, EMPA retains a P-O bond and EA-2192 retains a P-S bond that may be susceptible to neutral hydrolysis, alkaline hydrolysis, or ammonolysis. While all three reaction mechanisms for EMPA and EA-2192 were considered (Table S1), only neutral hydrolysis is shown in Figure 3 for conciseness. This condition represents the scenario where most of the hydroxide ions are used up in the initial VX P-O/P-S bond cleavage, but excess water remains. 
Hydrolysis of the P-S bond in EA-2192 is shown to be thermodynamically favorable, with a $\otimes G$ value of $-12.25 \mathrm{kcal} / \mathrm{mol}$. This suggests that over long time periods, VX can be completely converted into non-toxic products in aqueous conditions. The organophosphorus product resulting from the P-S bond cleavage, EMPA, has a hydrolysis $\otimes G$ value near zero, suggesting that it will likely remain unreacted. The additional product resulting from the P-S bond cleavage, DESH, can dimerize in the presence of oxygen to form (DES) and additional water that can participate in the hydrolysis of VX and EA-2192. However, we note that this study does not examine transition state barriers, which could play an important role in the reaction of $\mathrm{O}_{2}$ with DESH to form the disulfide (DES) $)_{2}$. Nevertheless, this dimerized product has been detected experimentally [28].

Table 2 shows the comparison of the B3LYP and HF methods for reactions shown in Figure 3. Both methods suggest that the P-S $\left(\otimes G_{3}\right)$ and P-O $\left(\otimes G_{4}\right)$ bond cleavages are thermodynamically favorable. While the magnitude of the difference in $\otimes G$ value of the initial P-S and P-O bond cleavages is large, both methods suggest that the P-S bond cleavage is $\sim 10 \mathrm{kcal} / \mathrm{mol}$ more favorable than the $\mathrm{P}-\mathrm{O}$ bond cleavage. As a result, both methods are consistent with the experimental studies that report an 8:1 ratio of P-S to P-O bond cleavage during alkaline hydrolysis [6,28]. For the hydrolysis of EA-2192 and EMPA, both methods give similar $\otimes G$ values. As noted previously, the B3LYP/MIDI method is known to produce accurate geometries, but not necessarily accurate reaction energies. Previously, benchmarking showed that MIDI did in fact provide accurate geometries, but needed to be replaced with MP2/6-31+G(d) for accurate energy calculations [12]. Therefore, we expect that HF provides the more reliable energy calculations for this system. Although the two methods yield significantly different $\otimes G$ values in some cases, they both yield the same favorable reaction pathways.
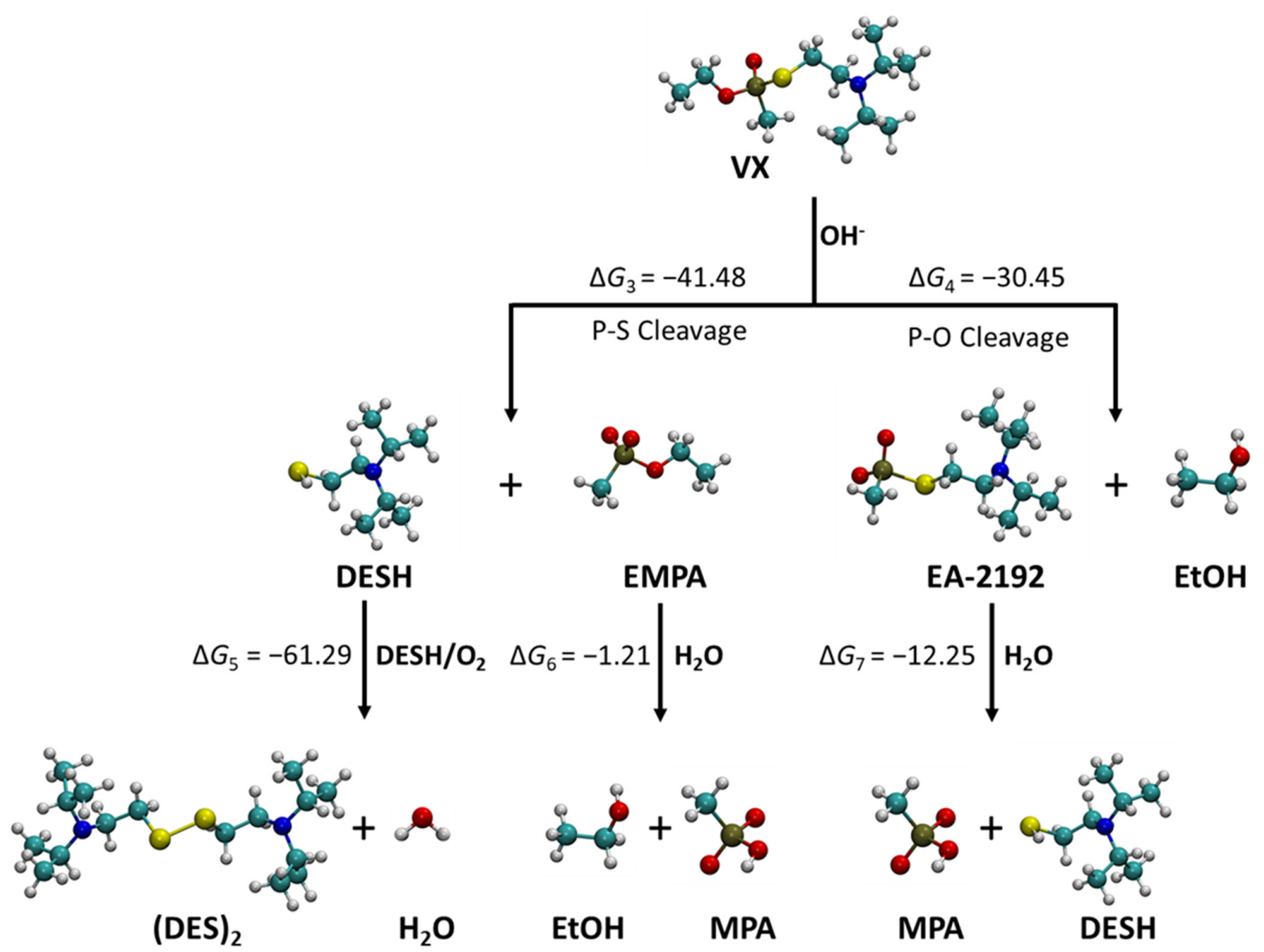

Figure 3. Full aqueous neutralization pathway for VX starting with an initial alkaline hydrolysis step. 
Table 2. Reaction-free energy comparison for various computational methods for the reaction pathways 3-7 in Figure 3.

\begin{tabular}{ccccc}
\hline & HF-S & HF & B3LYP-S & B3LYP \\
\hline$\otimes G_{3}$ & -41.48 & -77.58 & -87.18 & -114.18 \\
$\otimes G_{4}$ & -30.45 & -65.58 & -78.87 & -112.15 \\
$\otimes G_{5}$ & -61.29 & -52.74 & -42.84 & -41.28 \\
$\otimes G_{6}$ & -1.21 & -0.31 & -0.39 & 2.08 \\
$\otimes G_{7}$ & -12.25 & -12.31 & -8.71 & 0.05 \\
\hline
\end{tabular}

\subsection{Ammonolysis}

While multiple previous studies have looked at the alkaline hydrolysis of the P-S and $\mathrm{P}-\mathrm{O}$ bonds in VX, studies of the ammonolysis of VX are less common and have used related compounds rather than VX itself [24]. Ammonolysis of the P-S and P-O bonds of VX produce EMPAM and DIEMPAT, respectively. Out of all three reaction mechanisms, hydrolysis, alkaline hydrolysis, and ammonolysis, the latter has the least favorable $\otimes G$ values for cleaving the P-S and P-O bonds (Figure 4). As shown in Table 3, both HF and B3LYP methods show that ammonolysis of the P-O bond is unfavorable $\left(\otimes G_{9}\right)$; however, the methods conflict on the P-S bond cleavage $\left(\otimes G_{8}\right)$. Here, HF results in a modestly favorable $\otimes G$ of $-11.72 \mathrm{kcal} / \mathrm{mol}$ while B3LYP results in an unfavorable $\otimes G$ of $3.88 \mathrm{kcal} / \mathrm{mol}$. Despite the favorable reaction predicted by HF, ammonolysis of the $\mathrm{P}-\mathrm{S}$ bond is unlikely to have a significant effect on the overall neutralization of VX due to ammonolysis being the least-favorable reaction pathway.

Although the reaction of $\mathrm{VX}$ with $\mathrm{NH}_{3}$ was calculated to be either unfavorable (B3LYP) or only slightly favorable (HF), subsequent reactions were studied for completeness and for comparison with NMR and LC/MS product identification experiments. Once again, the products of the initial VX reaction can undergo neutral hydrolysis, alkaline hydrolysis, or ammonolysis; however, Figure 4 only shows alkaline hydrolysis for conciseness. Ammonolysis reaction-free energies of EMPAM and DIEMPAT are shown in Table S2. There are two possible routes each for alkaline hydrolysis of EMPAM and DIEMPAT. For EMPAM, the first is P-O bond cleavage, creating MPPAA and ethanol (EtOH). The second alkaline hydrolysis route involves attack of the P-N bond, resulting in EMPA and regenerating $\mathrm{NH}_{3}$. For DIEMPAT, alkaline hydrolysis can occur at the P-S bond, producing MPPAA and DESH, or at the P-N bond, creating EA-2192 and regenerating $\mathrm{NH}_{3}$. Both HF and B3LYP methods predict that all four routes of alkaline hydrolysis of EMPAM and DIEMPAT are favorable. Similar to EMPA and EA-2192 reactions (Table 2), the magnitude of the $\otimes G$ value predicted by B3LYP is much larger than that predicted by HF. It is also important to note that ammonolysis of VX followed by alkaline hydrolysis of the P-N bond produces the same products as alkaline hydrolysis of VX initially. If alkaline hydrolysis of the P-N bond is significantly faster than ammonolysis, it could be difficult to verify this ammonolysis pathway experimentally with a complex reaction mixture.

Table 3. Reaction free energy comparison for various computational methods for the reaction pathways 8-13 in Figure 4.

\begin{tabular}{ccccc}
\hline & HF-S & HF & B3LYP-S & B3LYP \\
\hline$\otimes G_{8}$ & -11.72 & -10.93 & 3.88 & 5.05 \\
$\otimes G_{9}$ & 1.49 & 8.34 & 14.32 & 16.61 \\
$\otimes G_{10}$ & -29.76 & -66.65 & -91.06 & -119.22 \\
$\otimes G_{11}$ & -24.60 & -56.11 & -73.08 & -98.64 \\
$\otimes G_{12}$ & -37.81 & -75.38 & -93.19 & -128.76 \\
$\otimes G_{13}$ & -31.94 & -73.92 & -83.52 & -110.20 \\
\hline
\end{tabular}




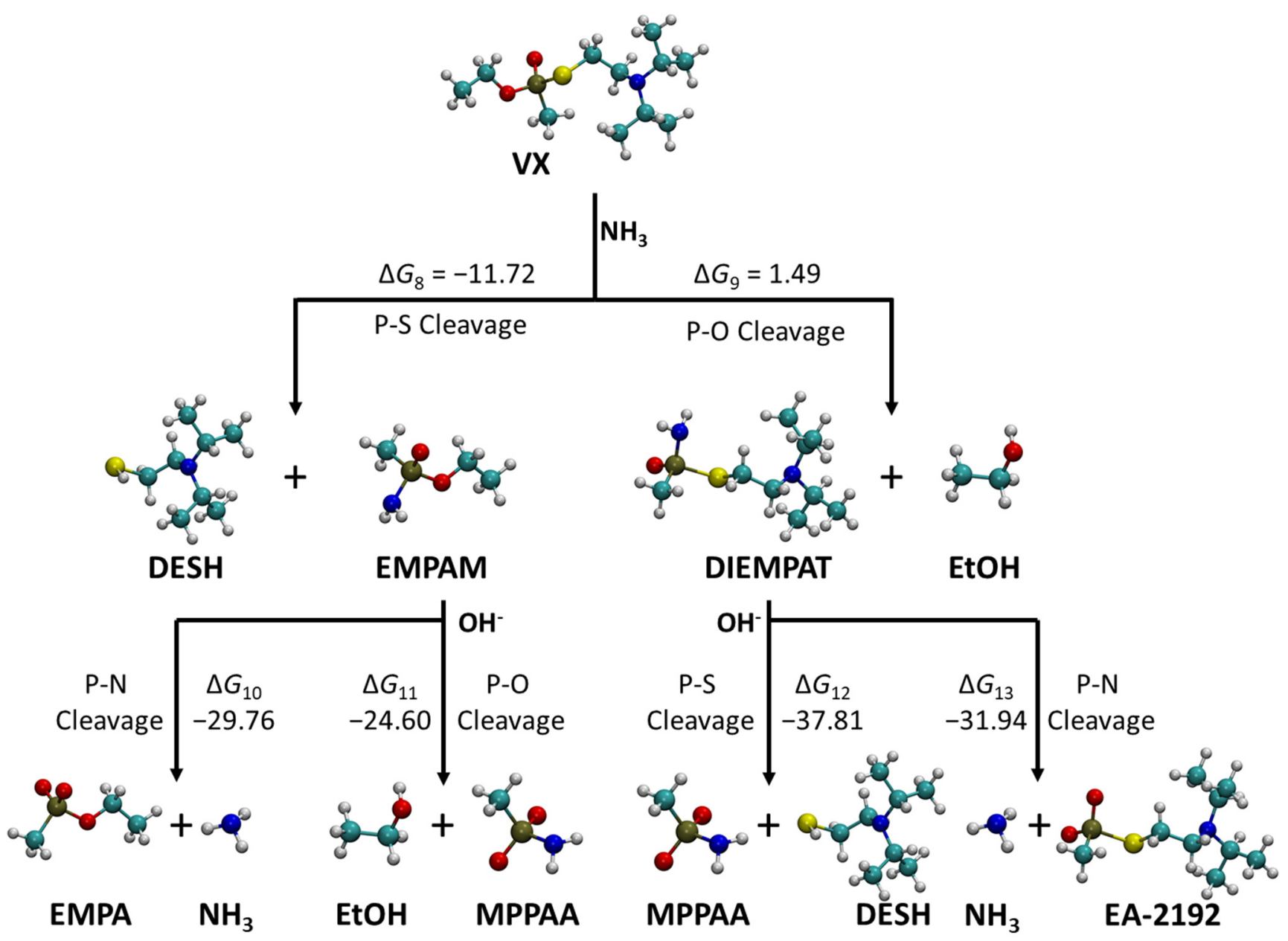

Figure 4. Full aqueous neutralization pathway for VX starting with an initial ammonolysis step.

\subsection{Computational and Experimental Agreement}

Figure 5 shows expected products and reaction free energies for the degradation of VX in alkaline conditions. Results are shown for calculations in the gas phase and with implicit solvent (water). Products shown in purple have been verified experimentally using the techniques P-31 NMR, C-13 NMR, and LC/MS [28]. In this reaction, $8 \mathrm{~g}$ of $\mathrm{Li}_{3} \mathrm{~N}$ tablets and $10 \mathrm{~mL}$ of water were added to $100 \mathrm{~mL}$ of VX. The VX was reduced to $6.6 \mathrm{wt} \%$ after one week and was undetectable after 3 months [28]. Both NMR techniques and LC/MS results confirmed the presence of EMPA. EA-2192 was identified by P-31 NMR and LC/MS, VX Disulfide by C-13 NMR, and diisoproylamine (DIPA) by C-13 NMR and LC/MS. Nevertheless, the presence of an experimentally verified product does not always ensure that a specific reaction has occurred as many routes can lead to the same products.

Cleavage of either the P-S or P-O bond by $\mathrm{OH}^{-}$is predicted to be energetically favorable, and confirmed experimentally by the presence of intermediates EMPA, DESH, and EA-2192 in the reaction mixture. The subsequent reactions of EA-2192 and EMPA with $\mathrm{OH}^{-}$are generally less favorable and may occur at a slower rate. The dimerization of DESH to form the (DES) 2 is predicted to be favorable. The observation of (DES) $)_{2}$ and DIPA substantiates the computational observation that oligomers do form as the reaction progresses. No additional computational reactions were performed to investigate continued oligomerization beyond three monomer units. The reaction of $\mathrm{VX}$ with $\mathrm{NH}_{3}$ is either unfavorable or only slightly favorable, as discussed above. However, alternative ammonolysis pathways resulting in $\mathrm{NH}_{3}$ could result in an autocatalytic process but a mechanism to increase the favorability of these reactions needs to be developed. Additional calculations to identify transition states for promising reaction pathways could be performed to obtain 
kinetic information for the initial steps. However, such calculations are beyond the scope of this work, whose purpose is to screen a large number of potential reaction pathways.

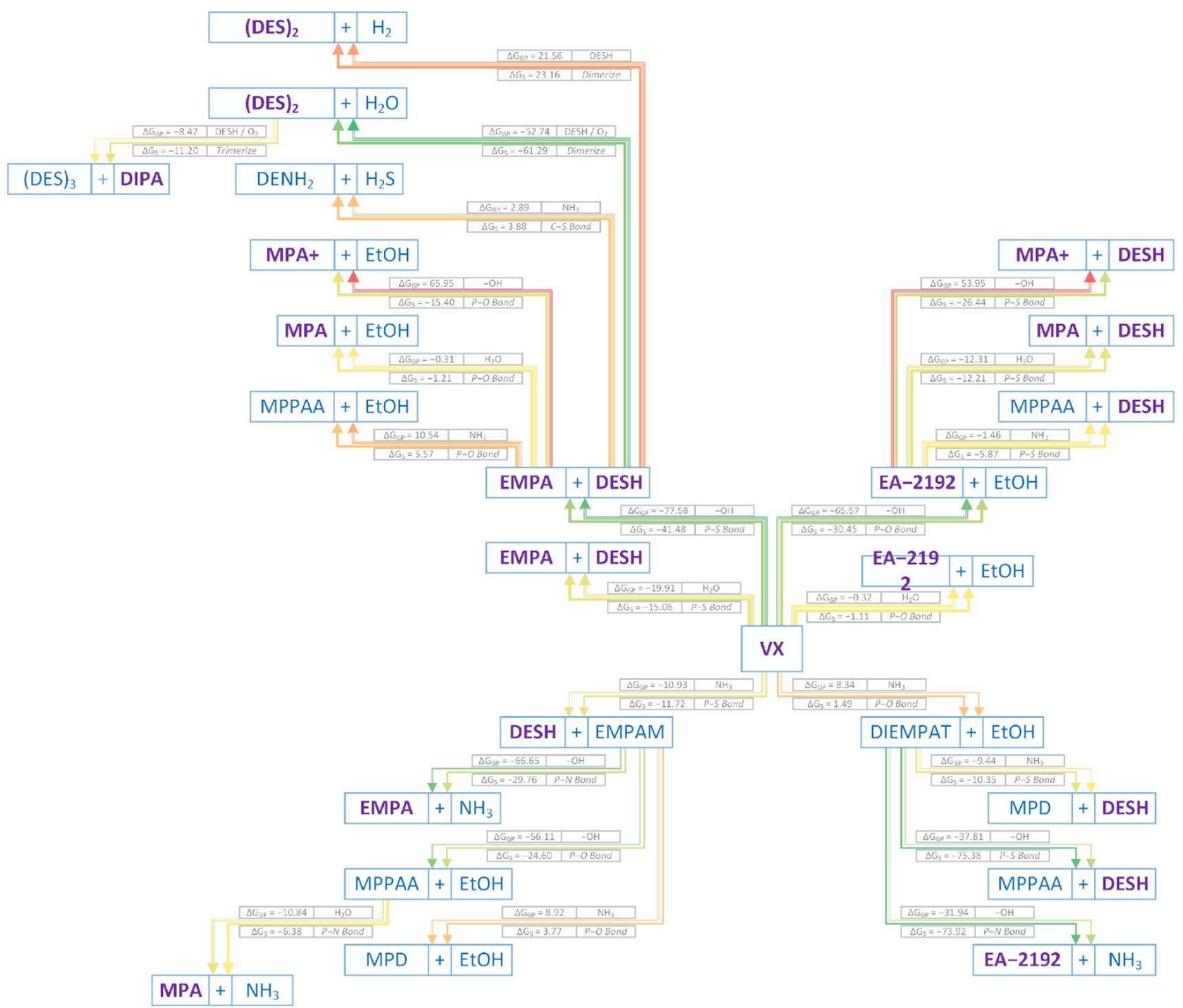

Figure 5. Reaction pathways for the complete degradation of VX in an alkaline environment. Reaction-free energies were obtained from HF calculations in gas phase (GP) and solvent (water, S) environments. Compounds in purple indicate species that have been detected experimentally. Reaction arrows are colored according to the reaction free energy values (green: Favorable, yellow: Slightly favorable or unfavorable, red: Unfavorable).

\section{Materials and Methods}

The reaction pathways were investigated with quantum mechanical calculations using the Gaussian 16 software suite [32]. The pathways examined include VX reactions with the nucleophilic hydroxide ions and ammonia molecules generated during the hydration of $\mathrm{Li}_{3} \mathrm{~N}$, rather than explicitly modeling $\mathrm{Li}_{3} \mathrm{~N}$ itself. All optimized geometries and harmonic frequencies were calculated using the HF level of theory for consistency with previous calculations on hydrolysis of similar compounds [10-12]. HF methods have been shown to predict reaction barrier heights poorly [33]. However, in this work, we use HF to compare reaction thermodynamics for stable intermediates and end products for several solvolysis mechanisms. We use an augmented polarized double zeta basis set $(6-31+G(d, p))[10]$, which is important to describe chemically inequivalent orbitals accurately. This basis set is considered one of the best double-zeta basis sets available [34]. For comparison, 
calculations were also performed at the DFT level of theory using the B3LYP functional with the MIDI! basis set, a computationally cheaper combination of valence basis functions and polarization functions that gives geometries and charges comparable to Moller-Plesset methods [35]. The B3LYP calculations included the empirical dispersion GD3BJ dampening function to account for nonbonded interactions [36]. Thermodynamic data were obtained from frequency calculations. The vibrational modes were checked for imaginary frequencies to ensure the optimized geometries were at local minima. Reaction-free energies, $\otimes G$, were calculated from the difference in free energies between the sum of reactants and products. To account for solvent effects and to more closely match experimental reaction studies, subsequent self-consistent reaction field (SCRF) analysis from the SMD implicit approximation with dielectric of water $(\varepsilon=78.35)$ was used for the HF calculations [37]. For the DFT calculations, the polarizable continuum model (PCM) was used to account for the solvent effects of water. In the solvated ammonolysis reactions, the free energy of ammonia is calculated in the solvated state, not the gas-phase. Therefore, no change in standard state from gas-phase to solution phase occurs. Molecular models were created using VMD [38].

\section{Conclusions}

The combination of $\mathrm{Li}_{3} \mathrm{~N}$ and water appears to be a promising method for the neutralization of bulk CWA fluids [28,29]. To provide molecular-level insight into potential reactions involved in this process, we studied the neutralization of CWA VX by neutral hydrolysis, alkaline hydrolysis, and ammonolysis using ab initio and DFT methods. Our calculations show alkaline hydrolysis as the most favorable mechanism, with a $\sim 10 \mathrm{kcal} / \mathrm{mol}$ preference for the P-S over the P-O cleavage for all methods. In aqueous solutions at the HF level of theory, we observe a slightly favorable $\otimes G$ for the P-S bond, but not the P-O bond, for both ammonolysis and neutral hydrolysis. This suggests that, over long periods of time, either water or $\mathrm{NH}_{3}$ can react with VX to produce exclusively non-toxic products. Finally, we studied further reactivity of the VX reaction products to determine the full reaction pathway. Those results were found to be in good agreement with, and complementary to, experimental studies. Many experimental products can be formed by multiple different reaction pathways, making it difficult to verify the reaction pathway from experiments alone.

Supplementary Materials: The following are available online at https:/ /www.mdpi.com/article/ 10.3390/ijms22168653/s1.

Author Contributions: Conceptualization, M.K.K., J.A.G. and S.B.R.; methodology, C.W.P., J.A.G. and S.B.R.; software, C.J.L., C.W.P. and S.B.R.; validation, C.J.L.; formal analysis, C.J.L.; investigation, C.J.L. and C.W.P.; resources, J.A.G. and S.B.R.; data curation, C.J.L.; writing-original draft preparation, C.J.L. and J.A.G.; writing-review and editing, C.J.L., J.A.G., M.K.K. and S.B.R.; visualization, C.J.L.; supervision, J.A.G..; project administration, M.K.K.; funding acquisition, M.K.K. All authors have read and agreed to the published version of the manuscript.

Funding: This research was funded and supported by the U.S. Department of Defense, Defense Threat Reduction Agency (DTRA)/Joint Science and Technology Office (JSTO) under project CB10412.

Institutional Review Board Statement: Not applicable.

Informed Consent Statement: Not applicable.

Data Availability Statement: The data presented in this study are available on request from the corresponding author.

Acknowledgments: We thank William Creasy and Patrick Burton for their comments on the manuscript. We thank Glenn Lawson of DTRA/JSTO for his support of this project and Kevin Morrissey of the Decontamination Sciences Branch for contract support. This work was performed, in part, at the Center for Integrated Nanotechnologies, an Office of Science User Facility operated for the U.S. Department of Energy (DOE) Office of Science. Sandia National Laboratories is a multimission laboratory managed and operated by National Technology and Engineering Solutions of Sandia, 
LLC., a wholly owned subsidiary of Honeywell International, Inc., for the U.S. Department of Energy's National Nuclear Security Administration under contract DE-NA-0003525. The views expressed in this document are those of the authors and do not necessarily reflect the official policy or position of the U.S. Department of Defense, the U.S. DOE, or the U.S. Government.

Conflicts of Interest: The authors declare no conflict of interest.

\section{References}

1. Costero, A.M.; Parra, M.; Gil, S.; Gotor, R.; Martínez-Mañez, R.; Sancenón, F.; Royo, S. Selective Detection of Nerve Agent Simulants by Using Triarylmethanol-Based Chromogenic Chemodosimeters. Eur. J. Org. Chem. 2012, 2012, 4937-4946. [CrossRef]

2. Friboulet, A.; Rieger, F.; Goudou, D.; Amitai, G.; Taylor, P. Interaction of an Organophosphate with a Peripheral Site on Acetylcholinesterase. Biochemistry 1990, 29, 914-920. [CrossRef]

3. Shih, T.M.; Kan, R.K.; McDonough, J.H. In Vivo Cholinesterase Inhibitory Specificity of Organophosphorus Nerve Agents. Chem. Biol. Interact. 2005, 157-158, 293-303. [CrossRef] [PubMed]

4. Shen, T.; Tai, K.; Henchman, R.H.; McCammon, J.A. Molecular Dynamics of Acetylcholinesterase. Acc. Chem. Res. 2002, 35, 332-340. [CrossRef]

5. Simanenko, Y.S.; Savelova, V.A.; Prokop'eva, T.M.; Mikhailov, V.A.; Turovskaya, M.K.; Karpichev, E.A.; Popov, A.F.; Gillitt, N.D.; Bunton, C.A. Bis(Dialkylamide)Hydrogen Dibromobromate Precursors of Hypobromite Ion in Reactions with Nerve and Blister Agent Simulants. J. Org. Chem. 2004, 69, 9238-9240. [CrossRef]

6. Yang, Y.-C. Chemical Detoxification of Nerve Agent VX. Acc. Chem. Res. 1999, 32, 109-115. [CrossRef]

7. Bigley, A.N.; Xu, C.; Henderson, T.J.; Harvey, S.P.; Raushel, F.M. Enzymatic Neutralization of the Chemical Warfare Agent VX: Evolution of Phosphotriesterase for Phosphorothiolate Hydrolysis. J. Am. Chem. Soc. 2013, 135, 10426-10432. [CrossRef]

8. Tsai, P.C.; Fox, N.; Bigley, A.N.; Harvey, S.P.; Barondeau, D.P.; Raushel, F.M. Enzymes for the Homeland Defense: Optimizing Phosphotriesterase for the Hydrolysis of Organophosphate Nerve Agents. Biochemistry 2012, 51, 6463-6475. [CrossRef]

9. LeJeune, K.E.; Wild, J.R.; Russell, A.J. Nerve Agents Degraded by Enzymatic Foams. Nature 1998, 395, 27-28. [CrossRef] [PubMed]

10. Daniel, K.A.; Kopff, L.A.; Patterson, E.V. Computational Studies on the Solvolysis of the Chemical Warfare Agent VX. J. Phys. Org. Chem. 2008, 21, 321-328. [CrossRef]

11. Menke, J.L.; Patterson, E.V. Quantum Mechanical Calculations on the Reaction of Ethoxide Anion with O,S-Dimethyl Methylphosphonothiolate. J. Mol. Struct. THEOCHEM 2007, 811, 281-291. [CrossRef]

12. Seckute, J.; Menke, J.L.; Emnett, R.J.; Patterson, E.V.; Cramer, C.J. Ab Initio Molecular Orbital and Density Functional Studies on the Solvolysis of Sarin and O,S-Dimethyl Methylphosphonothiolate, a VX-Like Compound. J. Org. Chem. 2005, 70, 8649-8660. [CrossRef] [PubMed]

13. Glaude, P.A.; Melius, C.; Pitz, W.J.; Westbrook, C.K. Detailed Chemical Kinetic Reaction Mechanisms for Incineration of Organophosphorus and Fluoroorganophosphorus Compounds. Proc. Combust. Inst. 2002, 29, 2469-2476. [CrossRef]

14. Picard, B.; Chataigner, I.; Maddaluno, J.; Legros, J. Introduction to Chemical Warfare Agents, Relevant Simulants and Modern Neutralisation Methods. Org. Biomol. Chem. 2019, 17, 6528-6537. [CrossRef] [PubMed]

15. Nawała, J.; Jóźwik, P.; Popiel, S. Thermal and Catalytic Methods Used for Destruction of Chemical Warfare Agents. Int. J. Environ. Sci. Technol. 2019, 16, 3899-3912. [CrossRef]

16. Chauhan, S.; Chauhan, S.; D'Cruz, R.; Faruqi, S.; Singh, K.K.; Varma, S.; Singh, M.; Karthik, V. Chemical Warfare Agents. Environ. Toxicol. Pharmacol. 2008, 26, 113-122. [CrossRef]

17. Priest, C.W.; Greathouse, J.A.; Kinnan, M.K.; Burton, P.D.; Rempe, S.B. Ab Initio and Force Field Molecular Dynamics Study of Bulk Organophosphorus and Organochlorine Liquid Structures. J. Chem. Phys. 2021, 154, 084503. [CrossRef]

18. Emelianova, A.; Basharova, E.A.; Kolesnikov, A.L.; Arribas, E.V.; Ivanova, E.V.; Gor, G.Y. Force Fields for Molecular Modeling of Sarin and Its Simulants: Dmmp and Dimp. J. Phys. Chem. B 2021, 125, 4086-4098. [CrossRef]

19. Harvey, J.A.; McEntee, M.L.; Garibay, S.J.; Durke, E.M.; DeCoste, J.B.; Greathouse, J.A.; Sava Gallis, D.F. Spectroscopically Resolved Binding Sites for the Adsorption of Sarin Gas in a Metal-Organic Framework: Insights Beyond Lewis Acidity. J. Phys. Chem. Lett. 2019, 10, 5142-5147. [CrossRef]

20. Bermudez, V.M. Computational Study of the Adsorption of Trichlorophosphate, Dimethyl Methylphosphonate, and Sarin on Amorphous Sio2. J. Phys. Chem. C 2007, 111, 9314-9323. [CrossRef]

21. Jouypazadeh, H.; Farrokhpour, H. DFT and TD-DFT Study of the Adsorption and Detection of Sulfur Mustard Chemical Warfare Agent by the $\mathrm{C}_{24}, \mathrm{C}_{12} \mathrm{Si}_{12}, \mathrm{Al}_{12} \mathrm{~N}_{12}, \mathrm{Al}_{12} \mathrm{P}_{12}, \mathrm{Be}_{12} \mathrm{O}_{12}, \mathrm{~B}_{12} \mathrm{~N}_{12}$ and $\mathrm{Mg}_{12} \mathrm{O}_{12}$ Nanocages. J. Mol. Struct. 2018, 1164, $227-238$. [CrossRef]

22. Khan, M.A.; Kesharwani, M.K.; Bandyopadhyay, T.; Ganguly, B. Solvolysis of Chemical Warfare Agent VX Is More Efficient with Hydroxylamine Anion: A Computational Study. J. Mol. Graph. Model. 2009, 28, 177-182. [CrossRef] [PubMed]

23. Jang, Y.J.; Kim, K.; Tsay, O.G.; Atwood, D.A.; Churchill, D.G. Update 1 of: Destruction and Detection of Chemical Warfare Agents. Chem. Rev. 2015, 115, PR1-PR76. [CrossRef] [PubMed]

24. Mandal, D.; Sen, K.; Das, A.K. Aminolysis of a Model Nerve Agent: A Computational Reaction Mechanism Study of O,S-Dimethyl Methylphosphonothiolate. J. Phys. Chem. A 2012, 116, 8382-8396. [CrossRef] [PubMed]

25. Shan, X.; Sambrook, M.R.; Clary, D.C. Theoretical Study of Gas-Phase Unimolecular Decomposition of Simulants of the Nerve Agent VX. J. Phys. Chem. A 2019, 123, 59-72. [CrossRef] [PubMed] 
26. Yang, Y.-C.; Szafraniec, L.L.; Beaudry, W.T.; Bunton, C.A. Perhydrolysis of Nerve Agent VX. J. Org. Chem. 1993, 58, 6964-6965. [CrossRef]

27. Yang, Y.-C.; Szafraniec, L.L.; Beaudry, W.T.; Rohrbaugh, D.K. Oxidative Detoxification of Phosphonothiolates. J. Am. Chem. Soc. 1990, 112, 6621-6627. [CrossRef]

28. McGarvey, D.J.; Creasy, W.R.; Kinnan, M.K. Characterization of Solid Reaction Products from the Reaction of VX with $\mathrm{Li}_{3} \mathrm{~N}+\mathrm{H}_{2} \mathrm{O}$ for the Tactical Disablement Project; CCDC CBC-TR-1635; U.S. Army Combat Capabilities Development Command Chemical Biological Center: Aberdeen, MD, USA, 2020.

29. McGarvey, D.J.; Creasy, W.R.; Kinnan, M.K. Reaction of QL with Li3N+H2O for the Tactical Disablement Project; CCDC CBC-TR-1722; U.S. Army Combat Capabilities Development Command Chemical Biological Center: Aberdeen, MD, USA, 2020.

30. Yang, Y.-C.; Szafraniec, L.L.; Beaudry, W.T.; Rohrbaugh, D.K.; Procell, L.R.; Samuel, J.B. Autocatalytic Hydrolysis of V-Type Nerve Agents. J. Org. Chem. 1996, 61, 8407-8413. [CrossRef]

31. Smith, B.M. Catalytic Methods for the Destruction of Chemical Warfare Agents under Ambient Conditions. Chem. Soc. Rev. 2008, 37, 470-478. [CrossRef]

32. Frisch, M.J.; Trucks, G.W.; Schlegel, H.B.; Scuseria, G.E.; Robb, M.A.; Cheeseman, J.R.; Scalmani, G.; Barone, V.; Petersson, G.A.; Nakatsuji, H.; et al. Gaussian 16 Rev. C.01; Gaussian, Inc.: Wallingford, CT, USA, 2016.

33. Baker, J.; Andzelm, J.; Muir, M.; Taylor, P.R. OH $+\mathrm{H}_{2} \rightarrow \mathrm{H}_{2} \mathrm{O}+\mathrm{H}$. The Importance of 'Exact Exchange' in Density Functional Theory. Chem. Phys. Lett. 1995, 237, 53-60. [CrossRef]

34. Zhao, Y.; Pu, J.; Lynch, B.J.; Truhlar, D.G. Tests of Second-Generation and Third-Generation Density Functionals for Thermochemical Kinetics. Phys. Chem. Chem. Phys. 2004, 6, 673-676. [CrossRef]

35. Easton, R.E.; Giesen, D.J.; Welch, A.; Cramer, C.J.; Truhlar, D.G. The Midi! Basis Set for Quantum Mechanical Calculations of Molecular Geometries and Partial Charges. Theor. Chim. Acta 1996, 93, 281-301. [CrossRef]

36. Grimme, S.; Ehrlich, S.; Goerigk, L. Effect of the Damping Function in Dispersion Corrected Density Functional Theory. J. Comput. Chem. 2011, 32, 1456-1465. [CrossRef] [PubMed]

37. Marenich, A.V.; Cramer, C.J.; Truhlar, D.G. Universal Solvation Model Based on Solute Electron Density and on a Continuum Model of the Solvent Defined by the Bulk Dielectric Constant and Atomic Surface Tensions. J. Phys. Chem. B 2009, 113, 6378-6396. [CrossRef]

38. Humphrey, W.; Dalke, A.; Schulten, K. Vmd: Visual Molecular Dynamics. J. Mol. Graph. 1996, 14, 33-38. [CrossRef] 